\title{
Bacteremia due to Gordonia polyisoprenivorans: case report and review of literature
}

\author{
Xiurong Ding, Yanhua Yu, Ming Chen, Chen Wang, Yanfang Kang, Hongman Li and Jinli Lou*
}

\begin{abstract}
Background: Gordonia polyisoprenivorans is a ubiquitous aerobic actinomycetes bacterium that rarely cause infections in humans. Here, we report a case of G. polyisoprenivorans catheter-related bacteremia in an AIDS patient.

Case presentation: A 37-year-old man with a past medical history of AIDS-related lymphoma suffered bacteremia caused by a Gram-positive corynebacterium. The strain was identified as a Gordonia species by matrix-assisted laser desorption ionization-time of flight mass spectrometry and confirmed to G. polyisoprenivorans by $16 \mathrm{~S}$ rRNA combined with gyrB gene sequencing analyses. The patient was treated with imipenem and had a good outcome.

Conclusions: The findings from our case and previously reported cases indicate that malignant hematologic disease, immunosuppression, and indwelling catheter heighten the risk for G. polyisoprenivorans infection. Molecular methods should be employed for proper identification of G. polyisoprenivorans to the species level.
\end{abstract}

Keywords: Gordonia polyisoprenivorans, Bacteremia, Case report, AIDS

\section{Background}

Gordonia polyisoprenivorans is a ubiquitous grampositive coryneform bacterium belonging to the family Gordoniaceae in the order Actinomycetales [1]. It was first isolated in 1999 from stagnant water inside a deteriorated automobile tire [2]. G. polyisoprenivorans is well known for being the most effective rubber-degrading bacteria, but not as a common cause of bacteremia [3]. Here, we report a case of bacteremia caused by G. polyisoprenivorans in a patient with AIDS and review similar cases reported in the literature to summarize the important features of this disease.

\section{Case presentation}

A 37-year-old man with a past medical history of AIDSrelated lymphoma was admitted to Beijing Youan Hospital on 12 July 2016, for a relapse of diffuse large B cell lymphoma. The patient had been diagnosed with AIDS-related lymphoma 1 year earlier, and received eight courses of chemotherapy with rituximab, doxorubicin,

*Correspondence: loujinlilab@126.com

Department of Clinical Laboratory, Beijing Youan Hospital, Capital Medical University, Beijing 100069, China vincristine, and etoposide (R-EPOCH). The patient recovered well and was discharged, with advice for regular follow-up. Three months ago, the results of a positron emission tomography-computed tomography scan suggested lymphoma recurrence, and the patient was transferred to our institution with an indwelling central venous catheter (CVC) catheter that had been inserted 3 months earlier for administration of chemotherapy. After 3 days of chemotherapy with etoposide, ifosfamide, and cisplatin, the results of clinical laboratory tests revealed myelosuppression, with white cell count of $0.11 \times 10^{9} / \mathrm{L}$, hemoglobin of $4.0 \mathrm{~g} / \mathrm{dL}$, and platelet count of $8 \times 10^{9} / \mathrm{L}$. His body temperature had been abnormal for 2 days, reaching $38.6^{\circ} \mathrm{C}$ at the highest point, with procalcitonin of $0.96 \mu \mathrm{g} / \mathrm{L}, \mathrm{ESR}$ of $56 \mathrm{~mm} / \mathrm{h}$, and $\mathrm{CD}^{4+}$ T-lymphocyte count of $52 \times 10^{6}$ cells/L. A physical examination revealed no specific signs of infections or skin manifestations. Two sets of blood cultures, one from a peripheral vein and the other through the CVC (each $10 \mathrm{ml}$ in volume), were collected and sent to the laboratory for examination. The patient was started on empirical antimicrobial therapy with imipenem.

The blood culture drawn through the CVC was first flagged as positive by a BACTEC ${ }^{\mathrm{m}}$ FX instrument 
(Becton, Dickinson and Company, USA) after $38 \mathrm{~h}$ of incubation in an aerobic bottle. After $61 \mathrm{~h}$ of culture in an aerobic bottle, the peripheral blood culture also became positive. Direct microscopic examination based on Gram staining revealed the presence of nonsporulating beaded Gram-positive bacilli. Subcultured blood specimens were plated on sheep blood agar and MacConkey agar. On the sheep blood agar incubated at $35{ }^{\circ} \mathrm{C}$ in an aerobic environment with $5 \% \mathrm{CO}_{2}$, small white colonies became evident within $24 \mathrm{~h}$. After 3 days of incubation, the colonies became mucoid, and the colonies turned yelloworange. The bacteria were positive for catalase, negative for cytochrome oxidase activity, nonmotile, and unable to grow anaerobically.

Bacterial identification was performed by matrixassisted laser desorption ionization-time of flight mass spectrometry (MALDI-TOF MS) according to the manufacturer's instructions, and the obtained protein profiles were processed and analyzed by MALDI Biotyper 3.0 software (Bruker Daltonics, Germany). However, the MALDITOF MS failed to confidently identify the isolate to the species level. Nevertheless, the isolate was identified as a Gordonia species, with a top match score of 1.764 (for Gordonia rubripertincta; scores of $\geq 2.0$ and $<2.0$ to $\geq 1.7$ represent identification to the species level and genus level, respectively), suggesting it did not resemble any known Gordonia species in the database.

Thereafter, bacterial DNA extraction, PCR amplification, and DNA sequencing of the 16S rRNA with a universal primer pair were conducted to confirm the results. The obtained product sequence (1404 bp) was compared with published sequences in the GenBank database (http:// www.ncbi.nlm.nih.gov/blast). The results showed that the isolate had $99 \%$ matches with the type strains of G. polyisoprenivorans (strains W8130 and VH2), Gordonia bronchialis (strain DSM 43247), and Gordonia terrae (strain EY-T12). Sequencing of the gyrB genes was then performed according to a previous report [4]. The results showed that the $\operatorname{gyrB}$ gene of the isolate had $99.0 \%$ sequence identity with the gene sequence of the G. polyisoprenivorans strain, indicating that the isolate was G. polyisoprenivorans.

The isolate was sensitive to amikacin, ampicillin, amoxicillin-clavulanate, cefotaxime, imipenem, meropenem, ciprofloxacin, minocycline, linezolid, and vancomycin, with intermediate sensitivity to trimethoprim-sulfamethoxazole.

At 3 days after the start of imipenem therapy, there was a complete disappearance of fever and a remarkable improvement in the patient's clinical status. From day 5 onward, the patient was switched to oral antibiotics. As there was no swelling or effusion around the $\mathrm{CVC}$, the catheter was not removed. The patient was followed up for 3 months. There was no recurrence of the infection during the follow-up period. However, he died after 3 months apparently from progression of his hematological malignancies.

\section{Discussion and conclusions}

In recent years, Gordonia species have increasingly been recognized as pathogens that cause human infections in both immunocompromised and immunocompetent individuals [5-7]. The major pathogenic Gordonia species are Gordonia sputi, G. bronchialis, and G. terrae [7-10]. Infection caused by G. polyisoprenivorans is very rare. Our review of the literature revealed only five cases of infections caused by G. polyisoprenivorans in patients aged $17-78$ years that were described in detail $[1,11-14]$. The clinical spectra of these cases, as well as that of our case, are summarized in Table 1. In all cases, the patients presented with systemic bacteremia and suffered from hematologic malignancies. Three of the five bacteremia cases were caused by a contaminated $\mathrm{CVC}$, and the other two cases had histories of indwelling medical devices. It was reported that G. polyisoprenivorans can use isoprene rubber as its sole source of carbon and energy, and can form biofilms on intravascular devices. Notably, Gordonia species have been most commonly reported as causes of indwelling device-associated infections $[6,14,15]$. Our patient's history of AIDS, hematologic malignancy, chemotherapy, and indwelling intravascular catheter may have predisposed him to this rare infection. Thus, all the aforementioned cases had hematologic malignancies and had undergone medical device implantation operations, which are generally known as major risk factors for bloodstream infections caused by G. polyisoprenivorans.

Using conventional microbiologic culture and biochemical analyses, Gordonia species are particularly difficult to identify to both the genus and species levels. They are sometimes dismissed as Corynebacteria, Nocardia, or Rhodococcus species [12, 13, 16, 17]. It is also believed that the incidence of Gordonia infections has been underestimated. In our review of the literature, all of the G. polyisoprenivorans isolates were confirmed to the species level by $16 \mathrm{~S}$ rRNA gene sequencing analyses, and sometimes also required combination with secA1 or gyr $B$ gene fragment sequencing. This could be one reason why there have been few reports on G. polyisoprenivorans infections in the clinic. In the present case, although MALDI-TOF MS failed to identify the isolate to the species level (G. polyisoprenivorans is not in the Biotyper 3.0 database), it did identify the isolate as a Gordonia species. Moreover, Lam et al. [17] reported that G. sputi and G. bronchialis can be confidently identified to the species level by MALDI-TOF MS. Therefore, we believe that with the continuous improvement and development of the database, MALDI-TOF MS will become a powerful tool for identifying Gordonia species, 
Table 1 Bloodstream infections of humans with Gordonia polyisoprenivorans and underlying conditions

\begin{tabular}{|c|c|c|c|c|c|c|c|}
\hline Case & Authors & $\begin{array}{l}\text { Age/ } \\
\text { Gender }\end{array}$ & $\begin{array}{l}\text { Yr of isolation } \\
\text { /Region }\end{array}$ & Type of infection & Identification method & $\begin{array}{l}\text { Underlying } \\
\text { conditions }\end{array}$ & Treatment \\
\hline 1 & $\begin{array}{l}\text { Verma P } \\
\text { et al. [11] }\end{array}$ & $78 / \mathrm{M}$ & 2003/USA & Endocarditis & $\begin{array}{l}\text { 16S rRNA gene sequence } \\
\text { and DNA-DNA hybridization }\end{array}$ & $\begin{array}{l}\text { HHT,MDS, } \\
\text { pancytopenia }\end{array}$ & imipenem and amikacin \\
\hline 2 & $\begin{array}{l}\text { Kempf VA } \\
\text { et al. [12] }\end{array}$ & $24 / F$ & 2004/Germany & $\begin{array}{l}\text { Bacteremia due to } \\
\text { CVC }\end{array}$ & $16 \mathrm{~S}$ rRNA gene sequence & $C M L, s / p-B M T$ & piperacillin-tazobactam \\
\hline 3 & $\begin{array}{l}\text { Langer AJ } \\
\text { et al. [13] }\end{array}$ & $17 / F$ & 2007/USA & $\begin{array}{l}\text { Bacteremia due to } \\
\text { CVCand pneumonia }\end{array}$ & $16 \mathrm{~S}$ rRNA gene sequence & AML & $\begin{array}{l}\text { vancomycin and ceftazidime; } \\
\text { ciprofloxacin and azithromycin }\end{array}$ \\
\hline 4 & $\begin{array}{l}\text { Gupta M } \\
\text { et al. [1] }\end{array}$ & $17 / F$ & 2008/USA & $\begin{array}{l}\text { pneumonia with } \\
\text { associated bacteremia }\end{array}$ & $16 \mathrm{~S}$ rRNA gene sequence & AML & $\begin{array}{l}\text { ciprofloxacin, zithromycin, } \\
\text { vancomycin, ceftazidime }\end{array}$ \\
\hline 5 & $\begin{array}{l}\text { Ramanan P } \\
\text { et al. [14] }\end{array}$ & $48 / \mathrm{M}$ & 2012/USA & $\begin{array}{l}\text { Bacteremia due to } \\
\text { CVC }\end{array}$ & 16S rRNA gene sequence & $\begin{array}{l}\text { AML, } \\
\text { s/p-allogeneic } \\
\text { PBSCT }\end{array}$ & ceftriaxone \\
\hline 6 & present & $37 / M$ & 2016/China & $\begin{array}{l}\text { Bacteremia due to } \\
\text { CVC }\end{array}$ & $\begin{array}{l}16 S \text { rRNA and gyrB gene } \\
\text { sequence }\end{array}$ & $\begin{array}{l}\text { AIDS-related } \\
\text { lymphoma }\end{array}$ & imipenem \\
\hline
\end{tabular}

$F$ female, $M$ male, $H H T$ hereditary hemorrhagic telangiectasia, $M D S$ myelodysplastic syndrome, $C M L$ chronic myelogenous leukemia, $B M T$ bone marrow transplant, $s / p$ status post, $A M L$ acute myelogenous leukemia, PBSCT peripheral blood stem cell transplant, AIDS Acquired Immune Deficiency Syndrome

and that increasing numbers of infections caused by Gordonia species will be found in the clinic.

There are no standardized recommendations for the treatment of infections caused by Gordonia spp. The available data suggest that Gordonia spp. are generally susceptible to many antimicrobial drugs $[5,6]$ In a report on the antimicrobial susceptibility of 13 clinical isolates and one type strain, Moser et al. [18] found that G. polyisoprenivorans had high susceptibility to amikacin, ampicillin, ceftriaxone, imipenem, amoxicillin-clavulanate, ciprofloxacin, vancomycin, and linezolid, but poor susceptibility to trimethoprim-sulfamethoxazole, clarithromycin, tigecycline, and minocycline, with $36-57 \%$ of tested isolates showing higher minimal inhibitory concentrations. The isolate in the report by Langer et al. [13] also showed resistance to trimethoprim-sulfamethoxazole. In the present case, we also found that $G$. polyisoprenivorans was insensitive to trimethoprim-sulfamethoxazole. However, in patients with AIDS, trimethoprim-sulfamethoxazole has never been prophylactically used to reduce the opportunity of infection. Therefore, the possibility for initial resistance of G. polyisoprenivorans to trimethoprim-sulfamethoxazole needs to be validated by a larger study in a clinic. It is also worth noting that $G$. polyisoprenivorans has strong biofilm formation ability. It has been clearly validated that sessile bacterial communities in biofilms exhibit decreased susceptibility to antibiotics compared with planktonic organisms, and that conventional susceptibility methods cannot accurately predict the actual susceptibility of organisms existing in a biofilm [19]. Thus, to prevent persistent infections, the resistance of $G$. polyisoprenivorans should be considered when selecting an appropriate treatment method. Under certain conditions, catheter removal may be the best approach.

In conclusion, G. polyisoprenivorans is a rare but emerging human pathogen that causes bloodstream infections in immunocompromised hosts. Malignant hematologic disease, immunosuppression, and indwelling catheter heighten the risk for G. polyisoprenivorans infection. As these bacteria are difficult to identify to the species level in routine laboratories, 16S rRNA gene sequencing techniques and MALDI-TOF MS are recommended for accurate diagnosis. Treatment of a $G$. polyisoprenivorans infection should be based on the results of in vitro susceptibility tests.

\section{Abbreviations \\ CVC: Central venous catheter; MALDI-TOF: Matrix-assisted laser desorption ionization-time of flight mass spectrometry}

\section{Acknowledgments}

We would like thank Dr. Zhizhong Liu (China Rehabilitation Research Center Clinical Laboratory), who played an important role in correctly identifying the pathogen.

Funding

None.

Availability of data and materials

The data supporting the conclusions of this article are included within the articlet.

Authors' contributions

XRD conceived the study, carried out most of the data collection, and drafted the manuscript. YHY participated in the data analysis and interpretation, and drafted the manuscript. JLL conceived the study, participated in the study design, and revised the manuscript. $\mathrm{MCH}, \mathrm{CHW}, \mathrm{YFK}$, and $\mathrm{HML}$ contributed to the data analysis. All authors read and approved the final manuscript.

\section{Competing interests}

The authors declare that they have no competing interests.

\section{Consent for publication}

Written informed consent for publication of the clinical details and any accompanying images/tables was obtained from the patient before his death. A copy of the consent form is available for review by the Editor of this journal.

Ethics approval and consent to participate Not applicable. 


\section{Publisher's Note}

Springer Nature remains neutral with regard to jurisdictional claims in published maps and institutional affiliations.

Received: 21 February 2017 Accepted: 5 June 2017

Published online: 12 June 2017

\section{References}

1. Gupta M, Prasad D, Khara HS, Alcid D. A rubber-degrading organism growing from a human body. Int J Infect Dis. 2010;14(1):e75-6.

2. Linos A, Steinbüchel A, Spröer C, Kroppenstedt RM. Gordonia polyisoprenivorans sp. nov., a rubber-degrading actinomycete isolated from an automobile tyre. Int J Syst Bacteriol. 1999;49(4):1785-91.

3. Hiessl S, Schuldes J, Thurmer A, Halbsguth T, Broker D, Angelov A, et al. Involvement of two latexclearing proteins during rubber degradation and insights into the subsequent degradation pathway revealed by the genome sequence of Gordonia polyisoprenivoransstrain VH2. Appl Environ Microbiol. 2012;78:2874-87.

4. Lin $C L$, Shen FT, Tan CC, Huang CC, Chen BY, Arun AB, et al. Characterization of Gordonia sp. strain CC-NAPH129-6 capable of naphthalene degradation. Microbiol Res. 2012;167(7):395-404.

5. Blaschke AJ, Bender J, Byington CL, Korgenski K, Daly J, Petti CA, et al. Gordonia species: emerging pathogens in pediatric patients that are identified by 165 ribosomal RNA gene sequencing. Clin Infect Dis. 2007; 45(4):483-6

6. Lai CC, Wang CY, Liu CY, Tan CK, Lin SH, Liao CH, et al. Infections caused by Gordonia species at a medical centre in Taiwan, 1997 to 2008. Clin Microbiol Infect. 2010;16(9):1448-53.

7. Kofteridis DP, Valachis A, Scoulica E, Christidou A, Maraki S, Samonis G. Hickman catheter-related bacteremia caused by Gordonia sputi in a patient with breast cancer. J Infect Dev Ctries. 2012;6(2):188-91.

8. Ma TK, Chow KM, Kwan BC, Lee KP, Leung CB, Li PK, et al. Peritoneal-dialysis related peritonitis caused by Gordonia species: report of four cases and literature review. Nephrology (Carlton). 2014;19(7):379-83.

9. Zhang HL, Cao B, Li J, Cheng Y, Wang XJ. Plastic expander-related gordonia sputi infection: case report and literature review. Biomed Environ Sci. 2015; 28(6):468-71.

10. Aoyama K, Kang Y, Yazawa K, Gonoi T, Kamei K, Mikami Y. Characterization of clinical isolates of Gordonia species in Japanese clinical samples during 1998-2008. Mycopathologia. 2009;168(4):175-83

11. Verma P, Brown JM, Nunez VH, et al. Native valve endocarditis due to Gordonia polyisoprenivorans: case report and review of literature of bloodstream infections caused by Gordonia species. J Clin Microbiol. 2006;44(5):1905-8.

12. Kempf VA, Schmalzing M, Yassin AF, et al. Gordonia polyisoprenivorans septicemia in a bone marrow transplant patient. Eur J Clin Microbiol Infect Dis. 2004;23(3):226-8.

13. Langer AJ, Feja K, Lasker BA, Hinrikson HP, Morey RE, Pellegrini GJ, et al. Investigation of an apparent outbreak of Rhodococcus equi bacteremia. Diagn Microbiol Infect Dis. 2010;67(1):95-100.

14. Ramanan P, Deziel PJ, Wengenack NL. Gordonia bacteremia. J Clin Microbiol. 2013:51(10):3443-7.

15. Pham AS, Dé I, Rolston KV, Tarrand JJ, Han XY. Catheter-related bacteremia caused by the nocardioform actinomycete Gordonia terrae. Clin Infect Dis. 2003;36(4):524-7.

16. Gil-Sande E, Brun-Otero M, Campo-Cerecedo F, Esteban E, Aguilar L, Garcíade-Lomas J. Etiological misidentification by routine biochemical tests of bacteremia caused by Gordonia terrae infection in the course of an episode of acute cholecystitis. J Clin Microbiol. 2006;44(7):2645-7.

17. Lam JY, Wu AK, Leung WS, Cheung I, Tsang CC, Chen JH, et al. Gordonia species as emerging causes of continuous-ambulatory-peritoneal-dialysisrelated peritonitis identified by $16 \mathrm{~S}$ rRNA and secA1 gene sequencing and matrix-assisted laser desorption ionization-time of flight mass spectrometry (MALDI-TOF MS). J Clin Microbiol. 2015;53(2):671-6.

18. Moser BD, Pellegrini GJ, Lasker BA, Brown JM. Pattern of antimicrobial susceptibility obtained from blood isolates of a rare but emerging human pathogen, Gordonia polyisoprenivorans. Antimicrob Agents Chemother. 2012;56(9):4991-3.

19. Costerton JW, Stewart PS, Greenberg EP. Bacterial biofilms: a common cause of persistent infections. Science. 1999;284(5418):1318-22.

\section{Submit your next manuscript to BioMed Central and we will help you at every step:}

- We accept pre-submission inquiries

- Our selector tool helps you to find the most relevant journal

- We provide round the clock customer support

- Convenient online submission

- Thorough peer review

- Inclusion in PubMed and all major indexing services

- Maximum visibility for your research

Submit your manuscript at www.biomedcentral.com/submit 